\title{
The Distribution of the Plains Spadefoot, Spea bombifrons, in Relation to Soil Type in Southwestern Manitoba
}

\author{
William B. PRESTON \\ 1336 Mathers Avenue, Winnipeg, Manitoba R3M 2J8 Canada
}

Preston, William B. 2009. The distribution of the Plains Spadefoot, Spea bombifrons, in relation to soil type in southwest Manitoba. Canadian Field-Naturalist 123(2): 107-111.

The distribution of the Plains Spadefoot, Spea bombifrons, in southwestern Manitoba appears to be determined by soil type. Preference is shown for coarse textured to moderately textured soils, followed by medium textured soils. Drainage appeared to be less important in regard to distribution.

Key Words: Plains Spadefoot, Spea bombifrons, distribution, soil texture, Manitoba.

In southwestern Manitoba the Plains Spadefoot, Spea bombifrons, reaches the northeastern limit of its known range. The first collection of this species in the province consisted of three immature specimens from southwest of Dauphin $\left(51^{\circ} 08^{\prime} \mathrm{N} ; 100^{\circ} 02^{\prime} \mathrm{W}\right)$, collected 25 July 1935 by C. M. Sternberg (Cook 1960; Cook and Hatch 1964). The next known collection was by D. R. M. Hatch, southwest of Oak Lake, of a male on 22 July 1963 (Cook and Hatch 1964). In 1971 I received 6 of 18 tadpoles collected on 27 July at Oak Lake $\left(49^{\circ} 46^{\prime} \mathrm{N} ; 100^{\circ} 38^{\prime} \mathrm{W}\right)$ by J. L. C. Harrison and D. McDonald. Specimens have since been reported from, then collected at, Lyleton $\left(49^{\circ} 03^{\prime} \mathrm{N} ; 101^{\circ} 11^{\prime} \mathrm{W}\right)$ (Preston 1982; Preston and Hatch 1986), and near Virden (49 51'N; 100 $\left.55^{\prime} \mathrm{W}\right)$ (Preston and Hatch 1986). They have also been reported from the Treesbank area $\left(49^{\circ} 39^{\prime} \mathrm{N}\right.$; 99 $\left.9^{\circ} 36^{\prime} \mathrm{W}\right)$ (Bredin, personal communication). During the present study spadefoots were observed near Melita $\left(49^{\circ} 16^{\prime} \mathrm{N}\right.$; $\left.100^{\circ} 59^{\prime} \mathrm{W}\right)$, Coulter $\left(49^{\circ} 05^{\prime} \mathrm{N} ; 100^{\circ} 59^{\prime} \mathrm{W}\right)$, and Lauder $\left(49^{\circ} 23^{\prime} \mathrm{N} ; 100^{\circ} 40^{\prime} \mathrm{W}\right)$ (the latter observation by K. De Smet, personal communication). The Lauder location was, however, not included in the study area.

The purpose of this study was to define the distribution of the Plains Spadefoot in Manitoba. Earlier, while driving slowly around the southwest part of the province one night during a steady, light rain, I noted that spadefoots were common on the roads in somewhat less than half of the area covered. The area I drove was from Melita $\left(49^{\circ} 16^{\prime} \mathrm{N} ; 100^{\circ} 59^{\prime} \mathrm{W}\right)$ to Pierson $\left(49^{\circ} 10^{\prime} \mathrm{N} ; 101^{\circ} 15^{\prime} \mathrm{W}\right)$ to Lyleton $\left(49^{\circ} 03^{\prime} \mathrm{N} ; 101^{\circ} 10^{\prime} \mathrm{W}\right)$ to Coulter $\left(49^{\circ} 05^{\prime} \mathrm{N} ; 100^{\circ} 59^{\prime} \mathrm{W}\right)$ to Waskada $\left(49^{\circ} 05^{\prime} \mathrm{N}\right.$; $\left.100^{\circ} 48^{\prime} \mathrm{W}\right)$ to Medora $\left(49^{\circ} 15^{\prime} \mathrm{N}\right.$; $\left.100^{\circ} 41^{\prime} \mathrm{W}\right)$, and back to Melita. None were seen in the area from Coulter to Waskada to Medora and from Medora to Melita (Figure 1). Weather conditions, ideal for observing spadefoots, were the same throughout. Examination of a surficial geology map of Manitoba (Map 81-1) revealed that the area where no spadefoots were seen consisted primarily of glacial till. The remainder of the area I had covered (where spadefoots were observed) con- sisted of deposits of silt, clay and sand. This led me to wonder how critical the soil type was to spadefoot distribution. Preliminary analysis using a more detailed surficial geology map of the region (Map 39-1961 Virden) indicated that spadefoots showed a definite preference for sandy soil. As there are a variety of sandy and silty soil types in the area, I determined what particular soil types the Plains Spadefoot prefers. Bragg (1965) commented that [in Oklahoma] the Plains Spadefoot is seldom "found in regions of sandy soils" and that they "live in areas of tight' soils, for the most part". He also comments on the effect of human activities (i.e., disturbance of the soil) on spadefoot distribution.

\section{Methods}

The trips to the study area were made at random, when I could get away from my desk. The dates and the times at which the trips were made are indicated in Table 1. I drove roads at night and recorded odometer readings where spadefoots were observed, as well as at reference points such as intersections and bridges. The most fruitful nights were those with a light rain, or after a rain (both relatively uncommon in that area), if the temperature was at least 12 degrees C. However I tried to avoid being out during heavy thunderstorms or heavy rain, when visibility was greatly reduced. Bragg (1961) noted that "Spadefoot toads may remain underground for weeks at a time in dry weather...". Generally one to three field trips were made to the southwest per season, as time permitted, over several years, to collect data (Table 1). Although spadefoots were actually observed on paved or gravel roads, their presence there was assumed to be related to the soil type through which the road passed. It was also assumed that if spadefoot distribution was not related to soil type, that it would be more or less random in the area studied; i.e., the percentage of spadefoot observations in a particular soil type would be related to the percentage of the distance I travelled through that soil type, i.e. there is no relationship 


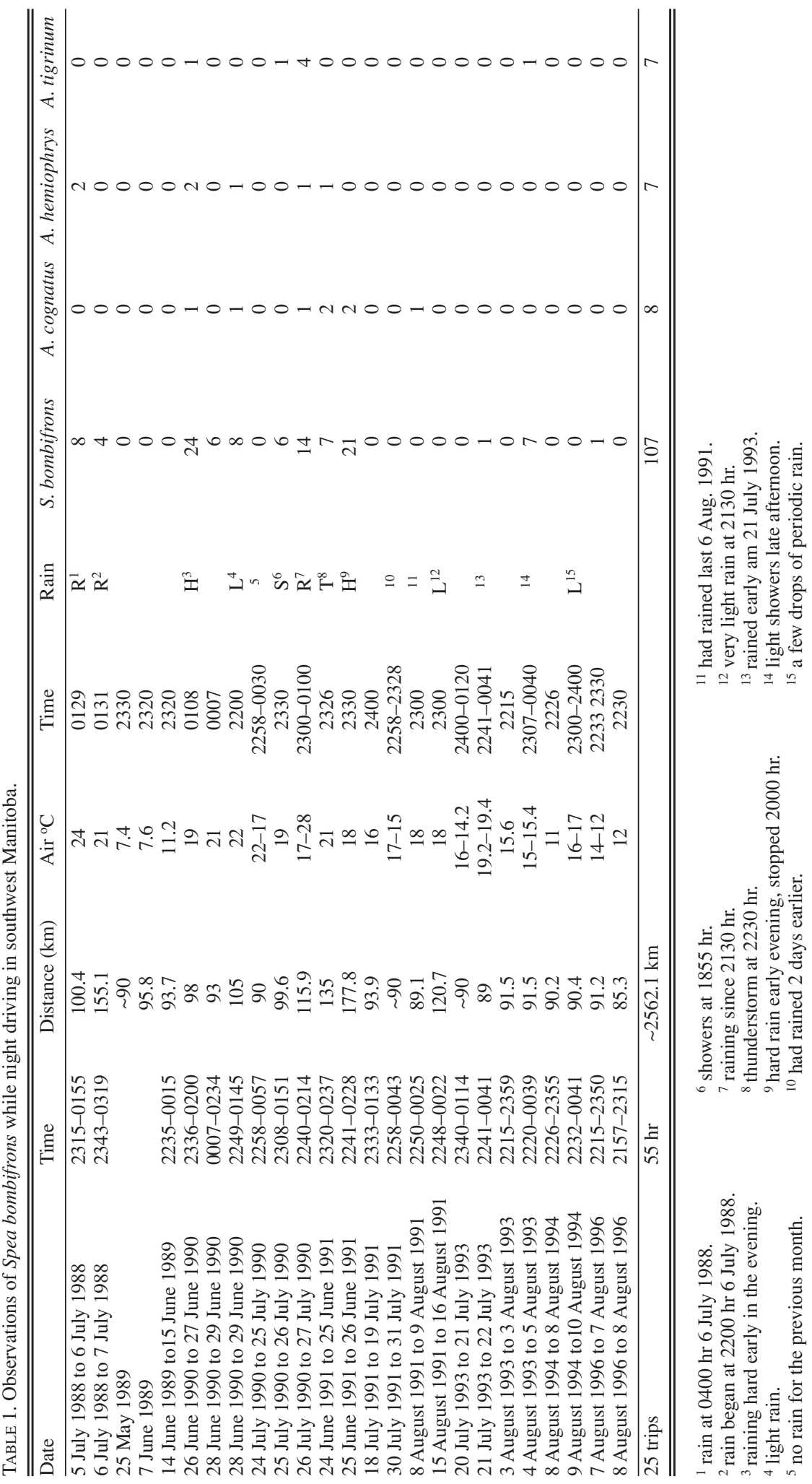


between spadefoot distribution and soil type (Null Hypothesis). This was tested using the chi-square method. A detailed soil map (Eilers et al, 1978) was used to perform an in-depth analysis. These maps use aerial photographs as backgrounds. The distance travelled through each soil type was measured on the maps in millimetres, using a dial calliper, and totalled for each soil type. The number of Plains Spadefoots observed within each soil type was totalled as well. For each soil symbol (soil name, or series), in addition to surface texture,Eilers et al (1978) provided details of drainage. For purposes of analysis, the list of 159 soil symbols (series) was reduced by combining those with the same soil texture (e.g., all those designated as loamy sand) and same drainage together, resulting in a list of 66 types, still rather cumbersome for analysis. Further combination took into account drainage only, and surface texture only (i.e., loamy sand, loamy very fine sand, etc.). Yet another list was made based on the physical surface texture such as fine textured, coarse textured, using definitions for such from Eilers et al (1978).Chi-square tests were performed on the data in these listings (Appendices I to VIII).

\section{Results}

In Table 1 the data is presented for each night drive (25 in total) conducted in the Melita - Lyleton area of southwest Manitoba. A total of 55 hours was spent driving a total distance of $2562.1 \mathrm{~km}$ (in the actual study area), during which 107 Spea bombifrons, 8 Anaxyrus cognatus, 7 Anaxyrus hemiophrys, 7 Ambystoma tigrinum, and one Lithobates sylvaticus were observed on the roads. It will be noted that, except for one occasion when one individual was observed at an air temperature of $12^{\circ} \mathrm{C}$, Spea was observed only at air temperatures of $15^{\circ} \mathrm{C}$ or higher, and especially after or during rain. On one drive $\mathrm{N}$ of Melita, after a light rain earlier in the day (8 August 1995), during which neither time nor mileage were noted, a number of Lithobates pipiens and Ambystoma tigrinum, perhaps 20 or so, of each, as well as two Anaxyrus hemiophrys, and one Pseudacris maculata were observed on the roads. No Spea bombifrons were observed in this area, however.

Analysis taking into account soil name (series), surface texture, and drainage, which included 159 categories in the study area, (Appendix I), indicated that there may be a relationship between these and spadefoot distribution. If only surface texture and drainage are taken into account, the soil names (series) having been combined under surface texture, reducing the number of categories to 66 (Appendix II), there is still an apparent relationship indicated between these and spadefoot distribution.

To determine if drainage was important, analysis was performed taking only drainage into account (Appendix III). Further analysis was performed, combining similar drainage types (Appendix V). There was ap-

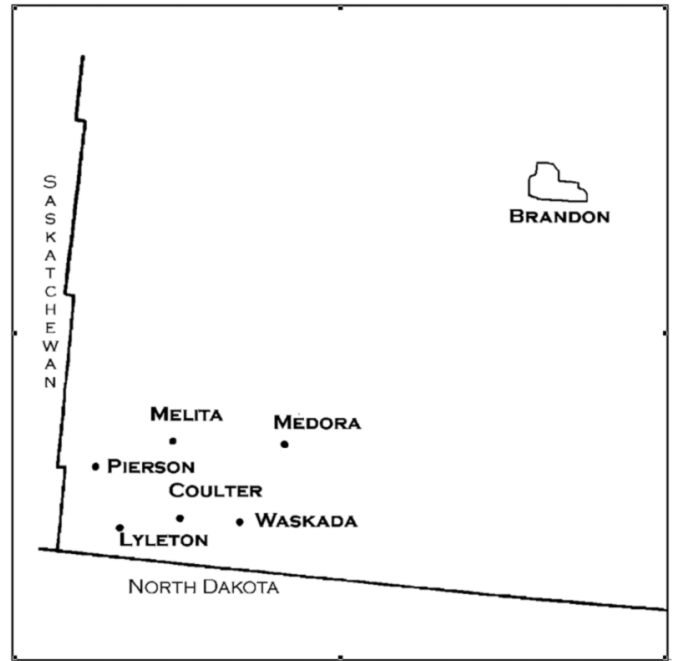

FIGURE 1. Map of southwest Manitoba indicating the study area. For scale, the distance between Melita and Medora is 35 kilometres.

parently little or no relationship between spadefoot distribution and drainage indicated.

\section{Discussion}

The Plains Spadefoot appears to show a preference for coarse textured to moderately coarse textured soils, with $56 \%$ of the observations occurring on these soils, which occupy $36 \%$ of the transect. The next preferred category appears to be medium textured soils, which occupy $42 \%$ of the transect, and on which $31 \%$ of the observations were made. The soil types most preferred were loamy sand, which occupies $22 \%$ of the transect, with $38 \%$ of the observations, and loam, occupying $41 \%$ of the transect, with $31 \%$ of the observations. Is it the physical texture of the soil or the soil type or chemical content that is important?

These findings do not appear to concur completely with Bragg's (1965) statement about soil associations. It is not clear what Bragg meant by "tight" soils; however Clayton et al. (1977) define tight soil as "a compact, relatively impervious and tenacious soil or subsoil, which may or may not be plastic." It should be pointed out that Bragg's observations were made in Oklahoma, and it may be that spadefoot requirements differ at the north edge of their range.

Drainage appeared to have little influence on spadefoot distribution, the percentage of spadefoots observed in the different drainage types being fairly close to the percentage of the transect covered by the drainage type. The greatest preference appeared to be for imperfectly drained soils, with $51 \%$ of the observations for this type, which occupies $38 \%$ of the transects surveyed. This is perhaps to be expected in that the loamy sand soils for which this species appears to show 
preference would tend to have less perfect drainage than sand.

Are the soil maps sufficiently accurate for a study of this kind? A recommendation for future research would be to collect a soil sample near the spot where each spadefoot is observed (perhaps one on each side of the road) and analyse these in regard to texture, soil type (i.e., loam, clay, etc.), and chemical content.

Knowing the preference of Spea bombifrons for loamy sand we can perhaps predict its distribution in southwest Manitoba, by consulting a soil map for the general area. Other than in the Dauphin area, this species appears to be limited to the Antler River-Lake Souris Plain in southwest Manitoba, bounded generally by the 450 metre contour.

\section{Acknowledgments}

I thank the Manitoba Museum Foundation Fund for financial support and encouragement of this project. I thank the Manitoba Museum of Man and Nature for the time and some financial support. I thank John Murray, of Lyleton, who has informed me on numerous occasions when heavy rains had occurred and when spadefoots were calling. I also thank Heather Groom, geologist, who assisted me in obtaining a surficial geology map of the study area. Also, I thank K. W. Stewart and another referee who provided many good suggestions for improvement of this manuscript.

\section{Appendix I. Spea distribution in relation to Soil Type (Soil Name), Surface Texture and Drainage.}

In this analysis all 159 map symbols, and combinations thereof,that occurred in the study area were used. These included Soil Name, Surface Texture and Drainage, as well as whether the soil was saline.

$\mathrm{H}_{0}$ : There is no relationship between spadefoot distribution and Soil Type, Surface Texture and Drainage.

$$
\begin{gathered}
\mathrm{Chi}^{2}=405.3707238 \\
\mathrm{df}=159-1=158 \\
\mathrm{t} \text { Ratio }{ }^{1}=10.669028 \\
\mathrm{P}<0.001 \quad(\text { Table A., Friedman 1972) }
\end{gathered}
$$

$\left({ }^{1}\right.$ Calculated according to Friedman 1972, page 288)

Therefore the probability that $\mathrm{H}_{0}$ is correct is less than 0.001 .

\section{Appendix II. Spea distribution in relation to Surface Texture and Drainage.}

In this analysis the data were combined so that only surface texture (i.e.: loamy sand; clay; loam to clay loam; $70 \%$ loam, $30 \%$ loamy sand; etc. ${ }^{1}$ ) and drainage were taken into account. The Soil Name (e.g. Ok, Oak Lake; Pk, Plum Creek; etc.) was not taken into account. Soils of different names but in the same surface texture and drainage categories were combined.

( ${ }^{1}$ each of these was assumed to be different.)

\section{Literature Cited}

Bragg, A. N. 1961. A theory of the origin of spade-footed toads deduced principally by a study of their habits. Animal Behaviour, 9(3-4): 178-186.

Bragg, A. N. 1965. Gnomes of the Night, The Spadefoot Toads. University of Pennsylvania Press, Philadelphia. 127 pages

Clayton, J. S., W. A. Ehrlich, D. B. Cann, J. H. Day, and I. B. Marshall. 1977. Soils of Canada. Research Branch, Canada Department of Agriculture, Ottawa, Ontario.

Cook, F. R. 1960. New localities for the plains spadefoot toad, tiger salamander and the great plains toad in the Canadian prairies. Copeia 1960: 363-364.

Cook, F. R., and D. R. M. Hatch. 1964. A spadefoot toad from Manitoba. Canadian Field-Naturalist 78: 60-61.

Eilers, R. G., L. A. Hopkins, and R. E. Smith. 1978. Soils of the Boissevain-Melita Area. Soils Report 20, CanadaManitoba Soil Survey. Manitoba Department of Agriculture, and Canada Department of Agriculture. 204 pages.

Friedman, H. 1972. Introduction to Statistics. Random House, New York. 334 pages.

Preston, W. B. 1982. The Amphibians and Reptiles of Manitoba. Manitoba Museum of Man and Nature, Winnipeg. 128 pages.

Preston, W. B., and D. R. M. Hatch. 1986. The plains spadefoot, Scaphiopus bombifrons, in Manitoba. Canadian FieldNaturalist 100: 123-125.

Received 29 September 2006

Accepted 9 January 2010

$\mathrm{H}_{0}$ : There is no relationship between spadefoot distribution and Surface Texture and Drainage.

$$
\begin{gathered}
\mathrm{Chi}^{2}=243.71175 \\
\mathrm{df}=66-1=65 \\
\text { t Ratio }{ }^{2}=10.71985302 \\
\mathrm{P}<0.001(\text { Table A., Friedman 1972) }
\end{gathered}
$$

$\left({ }^{2}\right.$ Calculated according to Friedman 1972, page 288.)

Therefore the probability that $\mathrm{H}_{0}$ is correct is less than 0.001 .

\section{Appendix III. Spea distribution in relation to Drainage.}

In this analysis only drainage was taken into account, i.e.: imperfect; well; poor; imperfect-poor; poor-imperfect; wellimperfect; well-poor; imperfect-well; imperfect-?; wellimperfect-poor; and well-poor-imperfect. Each of these was assumed to be different. (Compare with Appendix V.)

$\mathrm{H}_{0}$ : There is no relationship between spadefoot distribution and Drainage.

$$
\begin{gathered}
\mathrm{Chi}^{2}=21.234087 \\
\mathrm{df}=11-1=10 \\
0.02>\mathrm{P}>.01
\end{gathered}
$$

Therefore the probability that $\mathrm{H}_{0}$ is correct is greater than 0.01 but less than 0.02 . 


\section{Appendix IV. Spea distribution in relation to Surface Texture.}

In this analysis all of the Surface Textures (i.e. loam; clay; loamy sand; etc.) that were the same were combined, regardless of drainage. (For further combination of Surface Textures see Appendix VI.)

$\mathrm{H}_{0}$ : There is no relationship between spadefoot distribution and Surface Texture.

$$
\begin{gathered}
\mathrm{Chi}^{2}=65.169875 \\
\text { df }=30-1=29 \\
\mathrm{P}<0.001
\end{gathered}
$$

Therefore the probability that $\mathrm{H}_{0}$ is correct is less than 0.001 .

\section{Appendix V. Spea distribution in relation to Drainage.}

In this analysis some of the drainage types were combined, i.e. imperfect-poor was assumed to be the same as poor-imperfect; and well-imperfect was assumed to be the same as imperfectwell. (Compare with Appendix III.)

$\mathrm{H}_{0}$ : There is no relationship between spadefoot distribution and Drainage.

$$
\begin{gathered}
\mathrm{Chi}^{2}=13.181409 \\
\text { df }=8-1=7 \\
0.10>\mathrm{P}>0.05
\end{gathered}
$$

Therefore the probability that $\mathrm{H}_{0}$ is correct is greater than 0.05 but less than 0.10 .

\section{Appendix VI. Spea distribution in relation to Surface Texture.}

In this analysis the various Surface Textures were further combined, however "loam" was kept separate from "loam saline". (Compare with Appendix IV.)

$\mathrm{H}_{0}$ : There is no relationship between spadefoot distribution and Soil Type.

$$
\begin{gathered}
\mathrm{Chi}^{2}=55.328026 \\
\mathrm{df}=17-1=16 \\
\mathrm{P}<0.001
\end{gathered}
$$

Therefore the probability that $\mathrm{H}_{0}$ is correct is less than 0.001 .

\section{Appendix VII. Spea distribution in relation to soil texture.}

In this analysis the Surface Textures were classified into 5 basic types, according to whether they were Coarse textured, Moderately coarse textured, Medium-textured, Moderately fine-textured, or Fine-textured (according to Eilers et al. 1978, page 197):

Coarse textured: sands, loamy sands, loamy fine sand Moderately coarse textured: loamy very fine sand, sandy loam, fine sandy loam

Medium-textured: very fine sandy loam, loam, silt loam, silt, sandy clay loam (light)

Moderately fine-textured: clay loam, silty clay loam, sandy clay loam (heavy)

Fine-textured: sandy clay, silty clay, clay

(Compare with Appendix VIII.)

$\mathrm{H}_{0}$ : There is no relationship between spadefoot distribution and soil texture.

$$
\begin{aligned}
& \mathrm{Chi}^{2}=39.69197 \\
& \text { df }=21-1=20 \\
& 0.01>\mathrm{P}>0.001
\end{aligned}
$$

Therefore the probability that $\mathrm{H}_{0}$ is correct is greater than 0.001 but less than 0.01 .

\section{Appendix VIII. Spea distribution in relation to soil texture.}

In this analysis the soil textures were combined, reducing them to 6 categories:

Coarse textured to moderately coarse textured (at least 50\%) Fine-textured

Moderately fine textured to fine textured

Medium textured (at least 50\%)

Moderately fine textured

Medium textured to Moderately fine textured (at least 50\%) (Compare with Appendix VII.)

$\mathrm{H}_{0}$ : There is no relationship between spadefoot distribution and Texture.

$$
\begin{gathered}
\mathrm{Chi}^{2}=20.82427 \\
\mathrm{df}=6-1=5 \\
\mathrm{P}<0.001
\end{gathered}
$$

Therefore the probability that $\mathrm{H}_{0}$ is correct is less than 0.001 . 